\title{
The Use of Solar Shading in a Nearly Zero-Energy Neighbourhood
}

\author{
Silke Verbruggen ${ }^{1, *}$, Jolien Hertoge ${ }^{1}$, Marc Delghust ${ }^{1}$, Jelle Laverge ${ }^{1}$, and Arnold Janssens ${ }^{1}$ \\ ${ }^{1}$ Ghent University, Faculty of Engineering and Architecture, Research group Building Physics, 9000 Ghent, Belgium
}

\begin{abstract}
The use of solar shading can have an important influence on the internal heat gains, especially in zero-energy buildings. However, the research in literature is almost uniquely focused on offices, while information on the use of solar shading in residential dwellings is lacking. Therefore, the solar shading behaviour of occupants of a nearly zero-energy social housing neighbourhood in Belgium is analysed. Data are gathered by solar shading logging with a building monitoring system, logbooks and cross-sectional surveys. In general, the solar shades were not often adjusted, with many of the solar shades either always opened or always closed. Clear seasonal influences were observed; however, the temperature and solar irradiance did not reveal a significant relationship with the use of the solar shading. This relationship could be biased by the fact that some of the occupants use the solar shades not to prevent solar heat gains but to darken the room in the evening (blinds). Since the shades are not often adjusted and are thus in the same position for a long time, the use is independent of the prevailing weather conditions. The position of the solar shades seems to be more influenced by the personal preference of the occupant than by external factors. Additional simulations, carried out with Modelica, showed that when the full capacity of the solar shades is used, the overheating can be decreased up to $29 \%$ in south oriented rooms. The possible negative impact on the heating demands can be neglected. This shows the necessity to correctly model the solar shading behaviour in residential buildings, especially in nearly zero-energy buildings, for which the cooling demands are increasingly important.
\end{abstract}

\section{Introduction}

The use of solar shading can have a significant influence on the thermal comfort of occupants in a building. Closing the solar shades is a passive way to decrease overheating and will reduce the cooling demand. The correct use of solar shading can contribute to considerable energy savings, especially in zero-energy buildings in which the cooling load is critical. Furthermore, the use of solar shading can as well attribute to the visual comfort in a building. By lowering shades, the overall brightness in the room can be reduced as well as glare (e.g. on computer screens). It can also provide more privacy. Raising the shades on the other hand increases the daylight levels, the visual room spaciousness and the views to the outside [1].

Many studies have been carried out on the solar shading behaviour in offices, however, information regarding residential dwellings is lacking. For offices different models have been developed to predict solar shading behaviour. A lot of these models are based on maintaining visual comfort [2-10], by using parameters as illuminance and irradiance. In a study of Haldi [5], which included both visual comfort and thermal comfort parameters, it was found that only visual comfort parameters had an significant impact on the solar shading behaviour. The occupancy in the offices influences the solar shading behaviour as well. More shading actions occur when occupants enter their office than during intermediate times $[2,3,5,9,11]$. There is no agreement about the frequency of actions upon departure. The orientation of the shades is as well of importance. Southand west-oriented shades will be most often closed in winter, while east-oriented shades will most often be closed in summer [6]. Higher closing values during winter can be explained by the fact that the solar altitude is low, allowing the sun to penetrate deeper into the room, which causes more glare problems. The solar altitude or orientation of the windows are therefore often included in solar shading models $[4,6]$.

It can be concluded that in offices the main reasons for using the solar shades are to provide visual comfort rather than to avoid overheating $[5,12]$. Since the research in literature is almost uniquely focused on offices, information on the use of solar shading in residential dwellings is lacking. In offices visual comfort is of upmost importance to be able to work. It can be assumed that visual comfort will be less of a driving force in residential buildings, while maintaining thermal comfort will be essential.

The cooling load is getting increasingly important in residential dwellings, with better insulated dwellings and

\footnotetext{
* Corresponding author: silke.verbruggen@ugent.be
} 
a changing climate. Therefore, it is necessary to get insight in the use of solar shades by occupants of residential buildings and how this use impacts the indoor climate.

\section{Methods}

\subsection{Case study}

The research was based on data collected from a nearly zero-energy social housing neighbourhood in Belgium $[13,14]$. The housing project was equipped with a building monitoring system which was linked to a mirrored server at Ghent University. The project, built between 2010 and 2015, consists of 106 apartments and 90 single family dwellings. Fifty houses underwent a deep renovation, the other dwellings were new built. The apartments and 39 houses are fitted with a balanced mechanical ventilation system with heat recovery (system D); the other dwellings have demand-controlled exhaust ventilation with trickle vents (system C).

The apartments are all shadowed by terrace overhangs and static horizontal shading devices on the south façade. Only the windows at the lateral sides of the apartment blocks are equipped with dynamic solar shades. The type of solar shading in the houses is different whether the south façade faces the garden or the street. When the south façade borders the garden, the windows on the ground floor are shaded by a static horizontal shading device and the upper windows are equipped with dynamic solar shades that are operated manually (Fig. 1 - left). When the south façade borders the street, all windows have dynamic solar shades (Fig. 1- right). The dynamic solar shades are manually controlled by a switch in the respective room. When the occupant hits the switch, the shades will be closed or opened.

\subsection{Data}

Data is gathered by solar shading sensors available in the monitoring system and by additional logbooks.

The solar shading sensors (S) are only installed in 14 houses. For these dwellings all bedrooms and bathrooms, and a few living rooms have dynamic solar shades. It is only possible to fully open or close the solar shades, no intermediate position is possible in these houses. For each shading device two logs are made: status open and status closed. Status open gives ' 1 ' when an opening action occurs and returns ' 0 ' when the solar shading is lowered. Status closed returns exactly the opposite. The monitoring begun in 2015, so data over a long period is available. However, some major problems were encountered with the logged data. All datasets contained several series of actions that followed very shortly after each other. These series go up to 161 registrations with only a couple of seconds between each registration. Such series appear in both datasets that are available for each solar shading ("status open" and "status closed"). The exact reason for this error remains unclear but may have something to do with the electronic contact in the switch. Furthermore, the "status open" dataset is not exactly the opposite of the "status closed" dataset. Some actions are registered in one dataset but not in the other one. It was uncertain if "status open" or "status closed" was the correct dataset. It was decided to use the "status open" data in the further analysis.

During the summer of 2018 (6 august to 4 September), a logbook study (LB) was carried out at the same site to supplement the data gathered through monitoring. The occupants of the neighbourhood were asked to write down every action they performed with the solar shades during the period of the study. For each window equipped with solar shades, they were given a paper (Fig. 2) on which they could fill out the date and time of performing an action, and mark the position they changed the solar shades to. In some houses it was possible to put the shades in an intermediate position, therefore five options were given to mark the position they changed the solar shades to: fully open, $1 / 4$ closed, $1 / 2$ closed, $3 / 4$ closed and fully closed. It needs to be noted that the social housing company asked the tenants not to put the solar shades at intermediate positions since this could cause damage to the windows. All occupants of the houses were asked to participate in the study, however, only 19 occupants did so. To check whether the participants filled out the logbooks correctly, different observations were performed during the study period. In the end only 10 of the 19 logbooks were assumed to be correct.

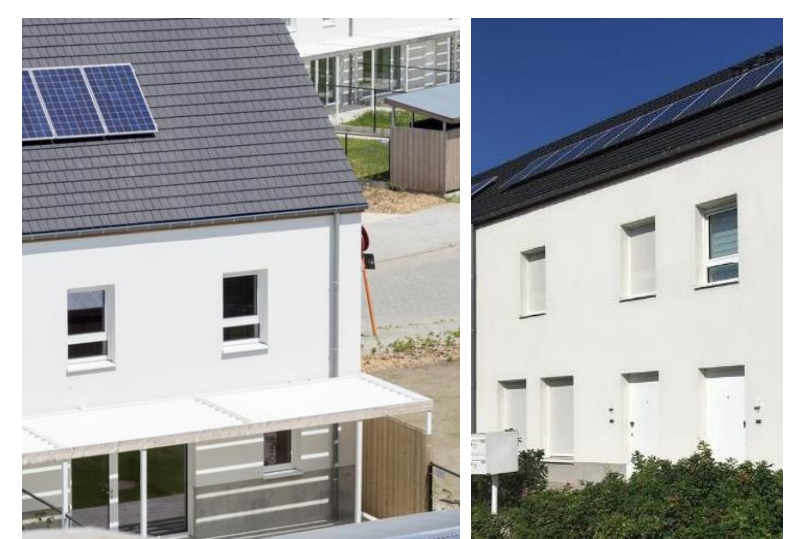

Fig. 1. Solar shading at a garden side facade (left) and at a street side facade (right)

\section{LOGBOEK ZONNEWERING}

Adres:

\begin{tabular}{|c|c|c|c|c|c|c|}
\hline $\begin{array}{l}\text { Datum } \\
\text { Date } \\
\text { Date }\end{array}$ & $\begin{array}{l}\text { Tijd } \\
\text { Time } \\
\text { Heure }\end{array}$ & & & & & \\
\hline$\ldots . / \ldots$. & $\ldots: \ldots$ & 0 & 0 & 0 & 0 & 0 \\
\hline$\ldots . / \ldots$ & $\ldots: \ldots$ & 0 & 0 & 0 & 0 & 0 \\
\hline$\ldots . / \ldots$. & $\ldots: \ldots$ & 0 & 0 & 0 & 0 & 0 \\
\hline$\ldots . / \ldots$. & $\ldots: \ldots$ & 0 & 0 & 0 & 0 & 0 \\
\hline$\ldots . / \ldots$ & $\ldots: \ldots$ & 0 & 0 & 0 & 0 & 0 \\
\hline$\ldots . / \ldots$ & $\ldots: \ldots$ & 0 & 0 & 0 & 0 & 0 \\
\hline$\ldots . / \ldots$ & $\ldots: \ldots$ & 0 & 0 & 0 & 0 & 0 \\
\hline
\end{tabular}

Fig. 2. Logbook solar shading use 


\section{Results}

\subsection{Frequency}

The first aspect that is considered is the frequency of shading adjustments. The average number of shading interactions per month is 4,97 (Fig. 3), as logged by the solar shading sensors. The solar shades in the living room and in the main bedroom are used most frequently. The number of actions includes both opening and closing actions. The low frequency of actions with the shades is in correspondence with literature on offices. Stazi et al. [15], and Foster and Oreszczyn [16], for example, noted that shades often remain in the same state for weeks or even months.

The logbook study was carried out for less than one month, so monthly averages are not available. The logbooks do confirm that in general little actions are taken on the solar shades. Seven out of the ten participating occupants never changed the position of one or more of the solar shades during the period that the study was carried out.

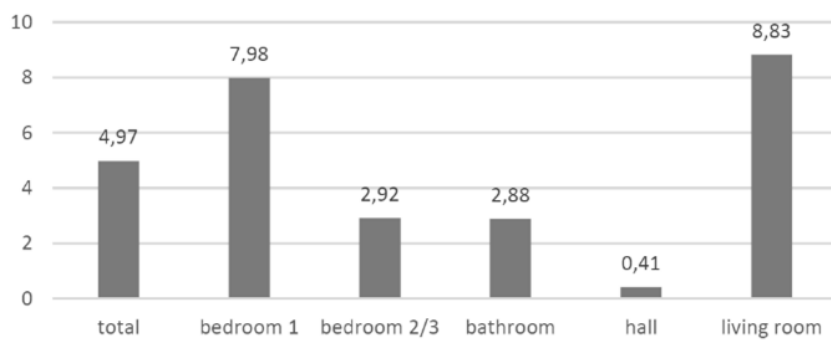

Fig. 3. Frequency of shading adjustments per month per $\operatorname{room}(\mathrm{S})$

\subsection{Time of day}

It was observed that most actions are performed in the morning, and in the evening (Fig. 4). This is in correspondence to findings in offices related to the occupancy $[2,3,5,9,11]$. When each case is assessed separately, different patterns could be distinguished. There are occupants that perform more closing actions in the morning and more opening actions in the evening (e.g. H1 Bedroom, Fig. 5). These occupants probably use their solar shades to limit overheating during the day. However, other occupants (e.g. H3 Bedroom, Fig. 6) perform more opening actions in the morning and closing actions in the evening. This indicates that they close the shades during the night probably to provide privacy or to make the room darker. In this study almost a quarter of the occupants (23\%) used the shades as blinds (Fig. 7).

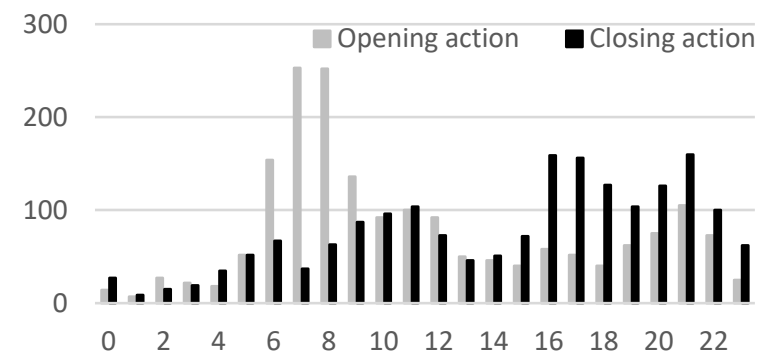

Fig. 4. Number of actions per hour of the day (S)

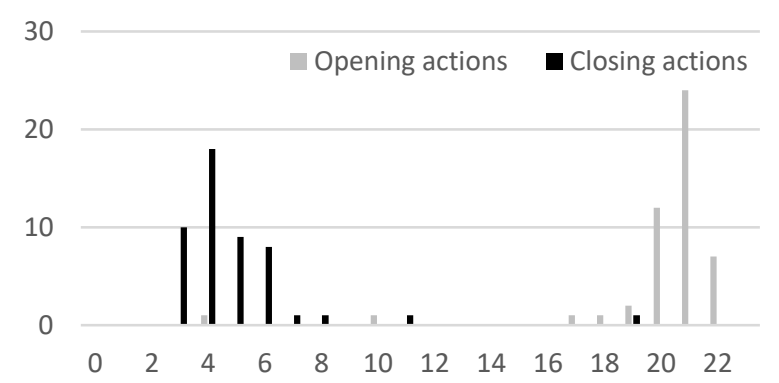

Fig. 5. H1 Bedroom - Number of shading adjustments per hour of the day (S)

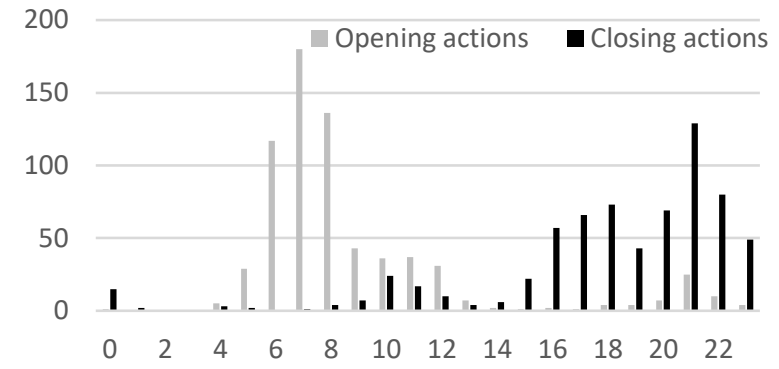

Fig. 6. H3 Bedroom - Number of shading adjustments per hour of the day (S)

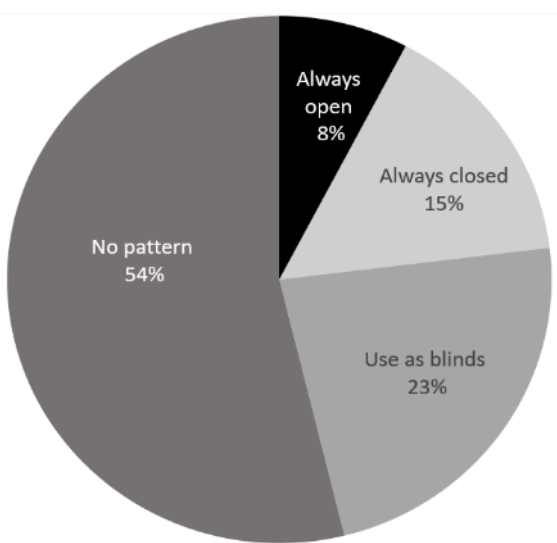

Fig. 7. Observed patterns of solar shading use based on sensor data (S)

\subsection{Closing percentage}

The total average closing percentage is $62 \%$ for the sensor data. In the living room (77\%), the main bedroom (71\%) and the bathroom (68\%) the solar shades are closed most often. For the bathrooms and the bedrooms, the difference in closing percentage varies a lot between the different houses; the values range from $2 \%$ to $100 \%$. As discussed previously a lot of the solar shades stay either always open or always closed. $38 \%$ of the observed solar shades remained closed for more than $90 \%$ of the time, of which $15 \%$ always stayed closed (Fig. 7). And $15 \%$ of the observed solar shades remained open for more than $90 \%$ of the time, of which $8 \%$ always remained open. Especially in the bathrooms a lot of the solar shades remain always closed. This can be attributed to the use of solar shades to provide privacy.

When solar shades are installed in both the bedroom and the bathroom, we see that the closing percentage is similar for both rooms in most cases. The closing 
percentage thus seems to be defined more by occupant preferences in general than by function of the room.

Even though the logbook study was carried out during summer, the total average closing percentage of the logbook study (57\%) (Table 1) is slightly lower than the average closing percentage obtained from the monitoring data. This difference can be attributed to the sample size. Since there are only a few responses, extreme values will have a large impact on the mean value.

Table 1. Closing percentage of each solar shade (LB)

\begin{tabular}{|c|c|c|c|c|c|}
\hline House & Bedroom & Bedroom 2 & Bedroom 3 & Bathroom & Living room \\
\hline H16 & & $0,00 \%$ & $0,00 \%$ & $0,00 \%$ & $0,00 \%$ \\
\hline $\mathrm{H} 17$ & & & & $100,00 \%$ & $0,00 \%$ \\
\hline H15 & $8,73 \%$ & & & $8,73 \%$ & \\
\hline $\mathrm{H} 1$ & & & & $100,00 \%$ & \\
\hline $\mathrm{H} 18$ & & & & $0,00 \%$ & $2,98 \%$ \\
\hline H19 & $100,00 \%$ & & & $100,00 \%$ & \\
\hline $\mathrm{H} 10$ & & $44,79 \%$ & & & \\
\hline $\mathrm{H} 2 \mathrm{O}$ & & $100,00 \%$ & $100,00 \%$ & & $100,00 \%$ \\
\hline $\mathrm{H} 21$ & & & & $64,82 \%$ & \\
\hline $\mathrm{H} 22$ & & $100,00 \%$ & $100,00 \%$ & & \\
\hline
\end{tabular}

\subsection{Weather variables}

The outdoor temperature and the solar irradiance were measured in a climate station on site. Additionally, the indoor temperature in the main bedroom and living room were measured in the houses. The influence of these parameters on the shading behaviour is analysed.

\subsubsection{Outdoor temperature}

The outdoor temperature was found to have a small positive correlation with the percentage of closed solar shades $(\tau=.095, p=.000)$ (Fig. 8$)$. More solar shades are closed when the temperature increases. However, the increase is small with approximately $5 \%$ more closed shades between $0{ }^{\circ} \mathrm{C}$ and $30^{\circ} \mathrm{C}$.

When the outdoor temperatures at the moment of opening is compared to the mean temperature of closing the solar shades, we notice that for all cases both actions happen averagely at the same temperature. The average outdoor temperature when opening a solar shade is $13,1^{\circ} \mathrm{C}$

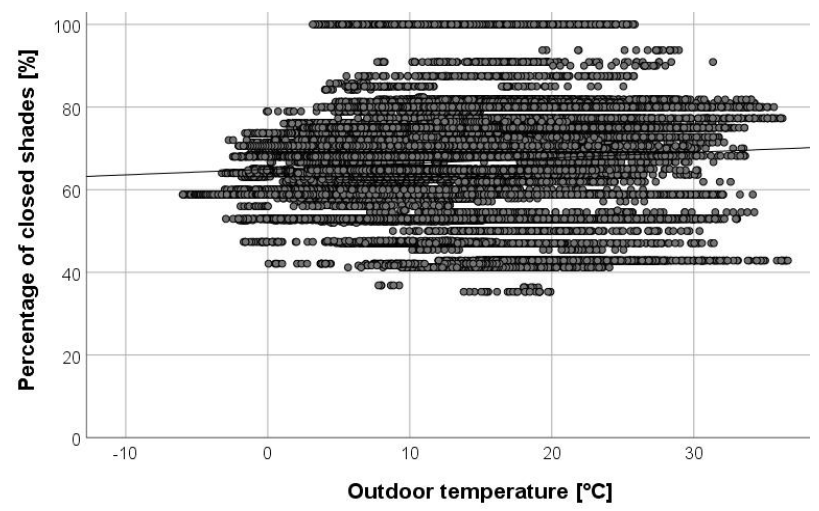

Fig. 8. Relationship temperature and percentage of closed solar shades (S) while the average outdoor temperature when closing a solar shade is $13,6{ }^{\circ} \mathrm{C}$. This can be attributed to the fact that many solar shades are not often used, and that most actions happen either in the morning or the evening, when lower temperatures are present.

\subsubsection{Indoor temperature}

One of the reasons for adjusting the solar shades is to preserve thermal comfort. Therefore, it seems plausible that the indoor temperature has an important influence on the shading behaviour. According to a study of Haldi and Robinson [9], the indoor temperature is a better parameter to predict shading behaviour than the outdoor temperature. Sutter et al. [8] found that for the same illuminance levels, the percentage of closed solar shades increased up to $30 \%$ for indoor temperatures higher than $26^{\circ} \mathrm{C}$ compared to indoor temperatures below $26^{\circ} \mathrm{C}$.

A small positive relationship is present between the indoor temperature and the closing percentage per day ( $\tau=$ $.039, \mathrm{p}=.000$ ) (Fig. 9). Indicating that solar shades are closed slightly more when the indoor temperature is higher. When the different rooms are analysed separately, only in the bedroom a significant positive relationship is present $(\tau=.060, \mathrm{p}=.000)$.

The opening and closing actions happen at approximately the same indoor temperature. The average indoor temperature when opening a solar shade is $22,0^{\circ} \mathrm{C}$, while the average indoor temperature when closing a solar shade is $22,1^{\circ} \mathrm{C}$.

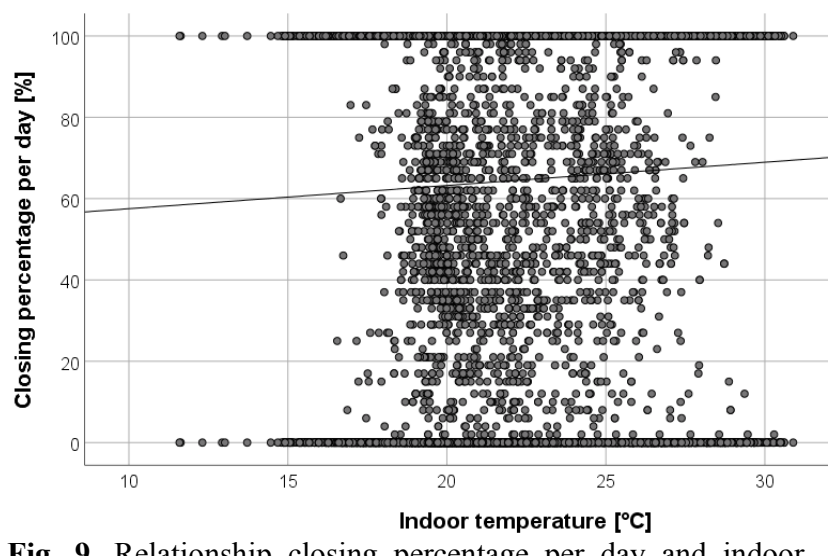

Fig. 9. Relationship closing percentage per day and indoor temperature

\subsubsection{Solar irradiance}

Solar irradiance is the parameter that was often defined in literature as most influential on the shading behaviour in offices. In offices visual comfort was found to be the biggest reason to adjust the solar shades, rather than thermal comfort. In these dwellings however, the solar shades are mostly installed in rooms where people are usually not present during the day (i.e. the bedroom, bathroom and hall). Therefore, it seems unlikely that a strong correlation would be present between the shading behaviour and the solar irradiance. 
Indeed, only a very small correlation between the percentage of closed solar shades and the solar irradiance is observed $(\tau=.038, \mathrm{p}=.000)$.

We can conclude that the weather variables have a small to negligible influence on the solar shading behaviour in this case study.

\subsection{Impact on indoor climate and energy use}

When the solar shades are closed, the heat gains are limited. In summer this leads to a decrease of overheating, while in winter this can result in a higher heat demand. To get an idea of the actual impact of the solar shading behaviour on the residential energy use, simulations are carried out with Modelica (Dymola) for a single family dwelling of the neighbourhood (Fig. 1). The simulated house is a two-storey two-bedroom house, insulated to nearly zero-energy standards. The impact on the indoor climate is studied through the annually amount of overheating in the house, expressed in Kelvin hours above $26^{\circ} \mathrm{C}$. In the Belgian EPBD-regulations, the overheating needs to be limited to $6500 \mathrm{Kh}$.

First, a comparison is made between the situation where the solar shades are always open and the situation where they are always closed. In this way the maximum possible impact of the solar shades can be examined. The windows remain closed at all times. Next, the simulations are carried out according to the assumption about solar shading behaviour that is made in the Belgian EPBDcalculations. The solar shades are assumed to be closed when the global horizontal solar irradiation is above $300 \mathrm{~W} / \mathrm{m}^{2}$. For this simulation, this results in a closing percentage of approximately $17 \%$. This is significantly lower that the real closing percentages obtained from the logbook study and monitoring data.

The resulting indoor temperatures for a simulation of one year with the solar shades always open, always closed and used according to EPBD are given in Fig. 10. When the solar shades are not used (always open), the overheating in the bedroom is $3904 \mathrm{Kh}$. This is still under the threshold of $6500 \mathrm{Kh}$. The overheating can maximally be reduced by the solar shading (always closed) to 1018 $\mathrm{Kh}$. This a reduction of $74 \%$ of the overheating. When the solar shading behaviour according to the EPBDcalculation is applied, an overheating of $2777 \mathrm{Kh}$ is obtained. The use of the solar shading according to EPBD leads therefore to a reduction in overheating of only $29 \%$ in comparison to not using the solar shades.

The yearly heating demand in the house is $1818 \mathrm{kWh}$ when the solar shades are always open. This will be increased with only $275 \mathrm{kWh}(15 \%)$ when the solar shades are always closed.

From these simulations we can conclude that leaving the solar shades always closed can lead to a significant reduction in overheating, and the additional energy use related to keeping the solar shades closed is limited. However, visual comfort needs to be maintained as well. Many occupants prefer to let daylight in and have views to the outside. The opening behaviour as described in the EPBD-calculation only allows for a reduction of $29 \%$, while the potential is $74 \%$. Furthermore, this strategy requires adaptive actions every time the solar irradiance crosses the threshold of $300 \mathrm{~W} / \mathrm{m}^{2}$. This is unrealistic since most occupants are not always at home when the action should be taken. Therefore, a more occupant based solar shading strategy (e.g. closing solar shading in the morning and opening it when returning from work) could limit overheating better and is more realistic.

\section{Conclusion}

The solar shades are not often adjusted and are thus in the same position for a long time, independent of the temperature or solar irradiance. The position of the solar shades seems to be more influenced by the personal preference of the occupant than by external factors. This makes that predicting the position of the solar shades becomes difficult. A lot of occupants leave their solar shades open or closed for almost all the time. Furthermore, many occupants use the shades as blinds. The influence of the use of the solar shades on the indoor climate thus varies a lot between the houses. When the full capacity of the solar shades is used, the overheating in an energy-efficient building can be decreased up to $29 \%$ in south oriented rooms that are equipped with solar shades, while the possible negative impact on the heating demand can be neglected.

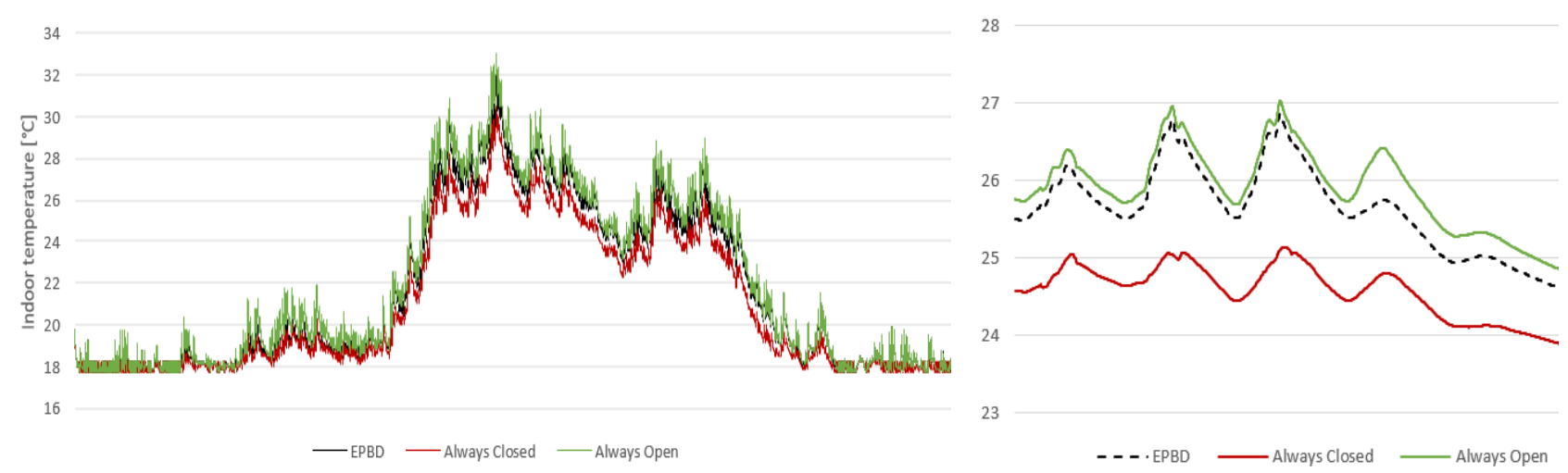

Fig. 10. Simulated indoor temperature for a year according to three solar shading strategies (left), zoom (right) 
We gratefully acknowledge the financial support received for this work from the Fund for Scientific Research (FWO) in the frame of the strategic basic research (SBO) project "NEPBC: Next generation building energy assessment methods towards a carbon neutral building stock" (S009617N). The authors would also like to thank the social housing company "Goedkope Woning' and the occupants of the social housing neighbourhood who willingly participated in this project.

\section{References}

[1] S.A. Sadeghi, P. Karava, I. Konstantzos, A. Tzempelikos, Build. Environ. 97, 177-195 (2016)

[2] C.F. Reinhart, Solar Energy 77, 15-28 (2004)

[3] C.F. Reinhart, Daylight availability and manual lighting control in office buildings : simulation studies and analysis of measurement (Fraunhofer-institut fur Solare Energiesysteme, Karlsruhe, 2001)

[4] A. Mahdavi, C. Pröglhöf, Building Simulation 2009, 537-544 (2009)

[5] F. Haldi, Towards a Unified Model of Occupants' Behaviour and Comfort for Building Energy Simulation (École Polytechnique Fédérale de Lausanne, Lausanne, 2010)

[6] Y. Zhang, P. Barrett, Build. Environ. 54, 137147 (2012)

[7] H.B. Gunay, W. O’Brien, I. BeausoleilMorrison, S. Gilani, Build. Environ. 113, 185199 (2017)

[8] Y. Sutter, D. Dumortier, M. Fontoynont, Energy Build. 38, 780-789 (2006)

[9] F. Haldi, D. Robinson, IBPSA 2009 - Int. Build. Perform. Simul. Assoc. 2009. 529-536 (2009)

[10] F. Haldi, D. Robinson, Build. Environ. 43, 2163-2177 (2008).

[11] P. Correia da Silva, V. Leal, M. Andersen, Build. Environ. 64, 152-168 (2013)

[12] I.A. Raja, J.F. Nicol, K.J. McCartney, M.A. Humphreys, Energy Build. 33, 235-244 (2001)

[13] E. Himpe, A. Janssens, J.E.V. Rebollar, Energy Procedia. 78, 3465-3470 (2015)

[14] A. Janssens, J. Vaillant Rebollar, E. Himpe, M. Delghust, Energy Procedia. 132, 549-554 (2017)

[15] F. Stazi, F. Naspi, M. D’Orazio, Build. Environ. 118, 40-66 (2017)

[16] M. Foster, T. Oreszczyn, Build. Environ. 36, 149-155 (2001) 